\title{
Aberrant methylation of the $G C K$ gene body is associated with the risk of essential hypertension
}

\author{
RUI FAN $^{1 *}$, WEI-JIE WANG ${ }^{2 *}$, QI-LONG ZHONG ${ }^{1}$, SHI-WEI DUAN ${ }^{1}$, \\ XU-TING XU ${ }^{1}$, LING-MEI HAO ${ }^{3}$, JING ZHAO ${ }^{1}$ and LI-NA ZHANG ${ }^{1}$ \\ ${ }^{1}$ Department of Preventive Medicine, Zhejiang Provincial Key Laboratory of Pathophysiology, School of Medicine, \\ Ningbo University; ${ }^{2}$ Department of General Medicine, Ningbo Baizhang Street Community Health Service Center; \\ ${ }^{3}$ Clinical Laboratory, The Seventh Hospital of Ningbo, Ningbo, Zhejiang 315211, P.R. China
}

Received June 25, 2014; Accepted March 20, 2015

DOI: $10.3892 / \mathrm{mmr} .2015 .3631$

\begin{abstract}
Essential hypertension (EH) is commonly accompanied by a dysfunction of glucose metabolism. Glucokinase (GCK) is a key enzyme involved in glucose metabolism. The aim of the present study was to investigate whether $G C K$ gene-body methylation contributed to the risk of EH. A total of 47 patients with $\mathrm{EH}$ and 47 age-matched controls were recruited for methylation research in the current study. GCK gene-body methylation was measured using bisulphite pyrosequencing technology. DNA methylation levels were closely correlated among $\mathrm{CpG} 1, \mathrm{CpG} 2$ and CpG3 ( $>0.70 ; \mathrm{P}<0.001)$, in contrast with a weaker correlation between $\mathrm{CpG} 4$ and the preceding three $\mathrm{CpGs}(\mathrm{r}<0.3$ or $\mathrm{r}=1 ; \mathrm{P}>0.05)$. Significantly lower $\mathrm{CpG1-3}$ methylation (cases vs. controls, $49.13 \pm 5.72$ vs. 53.49 $\pm 7.53 \%$; adjusted $\mathrm{P}=0.006)$ and significantly higher $\mathrm{CpG} 4$ methylation (cases vs. controls, $46.34 \pm 6.48$ vs. $34.74 \pm 12.73 \%$; adjusted $\mathrm{P}=0.002)$ were observed in patients with $\mathrm{EH}$. The present study indicated that aberrant methylation of the $G C K$ gene body was significantly associated with the risk of $\mathrm{EH}$ in the population assessed. The discrepancies between CpG1-3 and $\mathrm{CpG} 4$ methylation may suggest distinct roles for each of them in the determination of the risk of $\mathrm{EH}$.
\end{abstract}

\section{Introduction}

Hypertension is a major risk factor in cardiovascular disease and end-stage renal damage, and increases mortality rates

Correspondence to: Professor Li-Na Zhang or Mrs. Jing Zhao, Department of Preventive Medicine, Zhejiang Provincial Key Laboratory of Pathophysiology, School of Medicine, Ningbo University, 818 Fenghua Road, Ningbo, Zhejiang 315211, P.R. China E-mail: zhanglina@nbu.edu.cn

E-mail: zhaojing@nbu.edu.cn

*Contributed equally

Key words: GCK, gene body, methylation, essential hypertension worldwide (1). Essential hypertension (EH) is affected by genetic and environmental factors (2). Genetic factors are estimated to be responsible for 30 50\% of variations in blood pressure (BP) levels (3). Previous studies have identified multiple genetic loci associated with BP or hypertension in various ethnic populations $(4,5)$. Epidemiological studies have reported that multiple environmental factors are associated with risk of hypertension $(6,7)$.

Aberrant epigenetic modifications, including DNA methylation, may bridge the environmental and genetic contributing factors. Gene-body methylation was found to be positively correlated with gene expression (8). Although the functions of the gene-body $\mathrm{CpG}$ island (CGI) remain to be elucidated, methylation of the gene-body is frequently associated with active transcription in humans and other animals (9). Aberrant DNA methylation has been extensively investigated in the context of the pathogenesis of multiple types of cancer, including colorectal cancer (10), lung cancer (11) and leukemia (12). However, little evidence has demonstrated an association between DNA methylation and the risk of EH. A significant decline in global DNA methylation levels are observed in patients with EH and the trend continues alongside the progression of hypertension (13). In addition, altered global DNA methylation in the placentas of patients with pre-eclampsia was demonstrated to be associated with maternal hypertension (14). Aberrant DNA methylation of the $11 \beta$-HSD2, Adrbl and ADD1 genes was demonstrated to be associated with EH $(15,16)$.

Hypertension and diabetes are two closely associated, common diseases and their coexistence may increase the risk of cardiovascular disease (17). $G C K$, a candidate gene for type 2 diabetes (18), encodes glucokinase, which is a key enzyme involved in glucose metabolism $(19,20)$. The association between $\mathrm{EH}$ and $G C K$ polymorphisms was previously disclosed in several studies $(21,22)$. GCK gene-body hypomethylation was associated with the risk of coronary heart disease (23), which is closely correlated with $\mathrm{EH}(24,25)$. The present study performed an association study of $G C K$ gene-body methylation with the risk of $\mathrm{EH}$, in order to assess whether $G C K$ methylation is associated with $\mathrm{EH}$, and to examine the interactions between $G C K$ methylation and age, as well as clinical indicators. 


\section{Materials and methods}

Sample collection. Samples from a total of 47 patients with $\mathrm{EH}$ and 47 age-matched control individuals were collected from the community residents in Ningbo Baizhang Street Community Health Service Center (Zhejiang, China) and the Seventh Hospital of Ningbo (Zhejiang, China). The samples were collected from Han Chinese individuals, who had been living in Ningbo for a minimum of three generations. Hypertensive patients were defined according to the 'gold standard' (26). All the hypertensive patients had received antihypertensive medication for $>3$ months, or had at least three consecutive records of systolic blood pressure (SBP) $>140 \mathrm{mmHg}$ and/or diastolic blood pressure (DBP) $>90 \mathrm{mmHg}$ (26). Those patients exhibiting SBP $<120 \mathrm{~mm} \mathrm{Hg}$ and DBP $<80 \mathrm{mmHg}$, with no family history of hypertension in their first degree relatives were recruited as control individuals. The control individuals had not received antihypertensive therapy. The ages of the control individuals were matched with those of the patients with EH. None of the control or hypertensive individuals had a history of diabetes mellitus, secondary hypertension, myocardial infarction, stroke, renal failure, drug abuse or other serious diseases. A calibrated mercury sphygmomanometer with an adult-sized cuff was used to measure blood pressure according to the standard instructions recommended by the American Heart Association (27). Blood pressure was measured in supine position by two trained observers, with an interval of $\geq 10 \mathrm{~min}$. Following a $12 \mathrm{~h}$ overnight fast, blood samples were obtained from the antecubital vein using vacutainer tubes containing EDTA (Hebei Chaoran Medical Instrument Company, Baoding, China) and were stored at $-80^{\circ} \mathrm{C}$ for DNA extraction. All experiments were approved by the Ethics Committee of Ningbo University (Ningbo, China) and written informed consent was obtained from all subjects.

Biochemical analyses. A nucleic acid extraction analyzer (Lab-Aid 820; Zeesan Biotech, Xiamen, China) was used to extract genomic DNA from the peripheral blood samples. The concentration of extracted DNA was measured using an ultramicro nucleic acid ultraviolet tester (NanoDrop 1000; Thermo Fisher Scientific, Wilmington, DE, USA). Plasma levels of cholesterol, triglyceride (TG), alanine transaminase (ALT), aspartate transaminase, uric acid and glucose concentrations were enzymatically measured using a CX7 biochemical analyzer (Beckman Coulter, Brea, CA, USA). DNA methylation was measured using sodium bisulphite DNA conversion coupled with pyrosequencing (28). Briefly, genomic DNA was chemically modified by sodium bisulphite (EpiTech Bisulphite kit; Qiagen, Hilden, Germany) to convert all the unmethylated cytosines into uracils, while the methylated cytosines remained unchanged. The converted DNA were selected and the polymerase chain reaction (PCR) primers were designed with PyroMark Assay Design software, version 2.0.1.15 (Qiagen). The PCR products were subsequently degenerated using denaturation solution (Qiagen) and released to single strand products for pyrosequencing (29). PCR amplification was performed in reaction mixtures containing $10 \mu \mathrm{l} \mathrm{ZymoTaq}^{\mathrm{TM}}$ Premix (Zymo Research Corporation, Irvine, California, USA), $1.5 \mu$ l forward primer, $1.5 \mu \mathrm{l}$ reverse primer, $2 \mu \mathrm{l}$ converted DNA and $5 \mu \mathrm{l}$ DNAase/RNAase free water. PCR amplification was conducted using an Eppendorf Mastercycler Nexus Gradient (Eppendorf, Hamburg, Germany) under the following conditions: $95^{\circ} \mathrm{C}$ for $10 \mathrm{~min}$, then 40 cycles of $95^{\circ} \mathrm{C}$ for $30 \mathrm{sec}, 54.5^{\circ} \mathrm{C}$ for $40 \mathrm{sec}$ and $72^{\circ} \mathrm{C}$ for $50 \mathrm{sec}$, followed by one cycle of $72^{\circ} \mathrm{C}$ for $7 \mathrm{~min}$. The primer sequences were as follows: Forward, 5'-TGGATGGTTTAGTGTATAAGTTGTATT-3'; reverse, 5'-Biotin-CACCTCATCCTCC ACATTCAT-3' and sequencing primer, 5'-AAGTGGGGTTTAAAAAG-3'.

Statistical analyses. Statistical analyses were performed to investigate the association of $G C K$ methylation with metabolic profile and EH. A two sample t-test was performed to determine the association of $\mathrm{EH}$ with continuous variables, including age, body mass index, cholesterol, TG, glucose, ALT and uric acid. Pearson's correlation was used to determine the association between $G C K$ methylation and the biochemical indicators. A more conservative non-parametric approach was used for data which were unable to be normalized. Pearson's $\chi^{2}$ or Fisher's exact test was used to evaluate the association between $\mathrm{EH}$ and categorical variables, including gender, smoking and drinking. A receiver operating characteristic curve was used to examine the sensitivity of $G C K$ methylation in $\mathrm{EH}$ diagnosis. In addition, logistic regression was implemented to investigate the interactions between $G C K$ methylation and age. $\mathrm{P}<0.05$ was considered to indicate a statistically significant difference. The aforementioned statistical analyses were performed using PASW Statistics 19.0 software [SPSS (Honk Kong) Ltd., Hong Kong, China].

\section{Results}

In the present study, a fragment in the $G C K$ gene-body CGI, spanning exon 9 and a section of exon 10 (hg19, chr7: 44184771-44185695) was selected automatically by PyroMark Assay Design software for analysis. The results demonstrated that DNA methylation levels were closely correlated between CpG1, CpG2 and CpG3 (Fig. 1; r>0.70; P<0.001). By contrast a markedly weaker correlation was observed between $\mathrm{CpG} 4$ and the preceding three CpGs $(\mathrm{r}<0.3$ or $\mathrm{r}=1$; $\mathrm{P}>0.05)$.

As shown in Table I and Fig. 2, the results demonstrated that CpG1-3 methylation levels were significantly lower in samples from patients with $\mathrm{EH}$ (cases vs. controls, 49.13 \pm 5.72 vs. 53.49 $\pm 7.53 \%$; adjusted $\mathrm{P}=0.006$ ). By contrast, the $\mathrm{CpG} 4$ methylation levels were significantly higher in the samples from patients with $\mathrm{EH}$ (cases vs. controls, $46.34 \pm 6.48$ vs. $34.74 \pm 12.73 \%$; adjusted $\mathrm{P}=0.002$ ). No correlation was detected between $G C K$ DNA methylation and age amongst the patients or controls (data not shown), and no significant interactions of $G C K$ methylation and age were revealed to affect EH susceptibility ( $\mathrm{P}>0.05)$. Additionally, $\mathrm{CpG} 4$ methylation level was demonstrated to be an effective predictor of EH (Fig. 3; area under curve $\left.=0.769 ; \mathrm{P}=6.82 \times 10^{-6}\right)$, however, $\mathrm{CpG1}-3$ methylation was not a successful diagnostic marker of $\mathrm{EH}$ risk.

As shown in Table I, significant differences were observed in glucose ( $\mathrm{P}=0.001), \mathrm{TG}(\mathrm{P}=0.006)$, ALT $(\mathrm{P}=0.007)$ and uric acid $(\mathrm{P}=0.001)$ between $\mathrm{EH}$ cases and controls. In addition, gender-stratified correlation assessments were performed to assess the association between $G C K$ DNA methylation levels and metabolic phenotypes, including glucose, triglycerides, cholesterol, uric acid and ALT, in the control samples. A 
Table I. Characteristics of subjects.

\begin{tabular}{lccr}
\hline Characteristic & EH $($ Mean \pm SD) & Non-EH (Mean \pm SD) & P-value \\
\hline Age (years) & $59.34 \pm 7.20$ & $59.21 \pm 7.62$ & 0.934 \\
BMI (kg/m²) & $24.02 \pm 2.62$ & $22.52 \pm 4.08$ & 0.103 \\
Smoking (Y/N) & $7 / 40$ & $8 / 27$ & 0.356 \\
Alcoholic intake (Y/N) & $16 / 31$ & $5 / 30$ & 0.043 \\
Cholesterol (mmol/l) & $5.28 \pm 0.92$ & $5.04 \pm 1.07$ & 0.238 \\
TG (mmol/l) & $1.87 \pm 1.40$ & $1.31 \pm 0.83$ & 0.006 \\
Glucose (mmol/l) & $5.43 \pm 0.52$ & $5.23 \pm 0.92$ & 0.001 \\
ALT (IU/l) & $26.26 \pm 18.58$ & $18.17 \pm 12.14$ & 0.007 \\
Uric acid (mmol/l) & $363.71 \pm 84.82$ & $302.00 \pm 91.30$ & 0.001 \\
CpG1-3 methylation $(\%)$ & $49.13 \pm 5.72$ & $53.49 \pm 7.53$ & 0.002 \\
CpG4 methylation $(\%)$ & $46.34 \pm 6.48$ & $34.74 \pm 12.73$ & $4.78 \times 10^{-7}$
\end{tabular}

${ }^{\mathrm{a}} \mathrm{n}=94$ (47 EH vs. 47 Non-EH); EH, essential hypertension; SD, standard deviation; BMI, body mass index; Y, yes; N, no; TG, triglyceride; ALT, alanine transaminase.

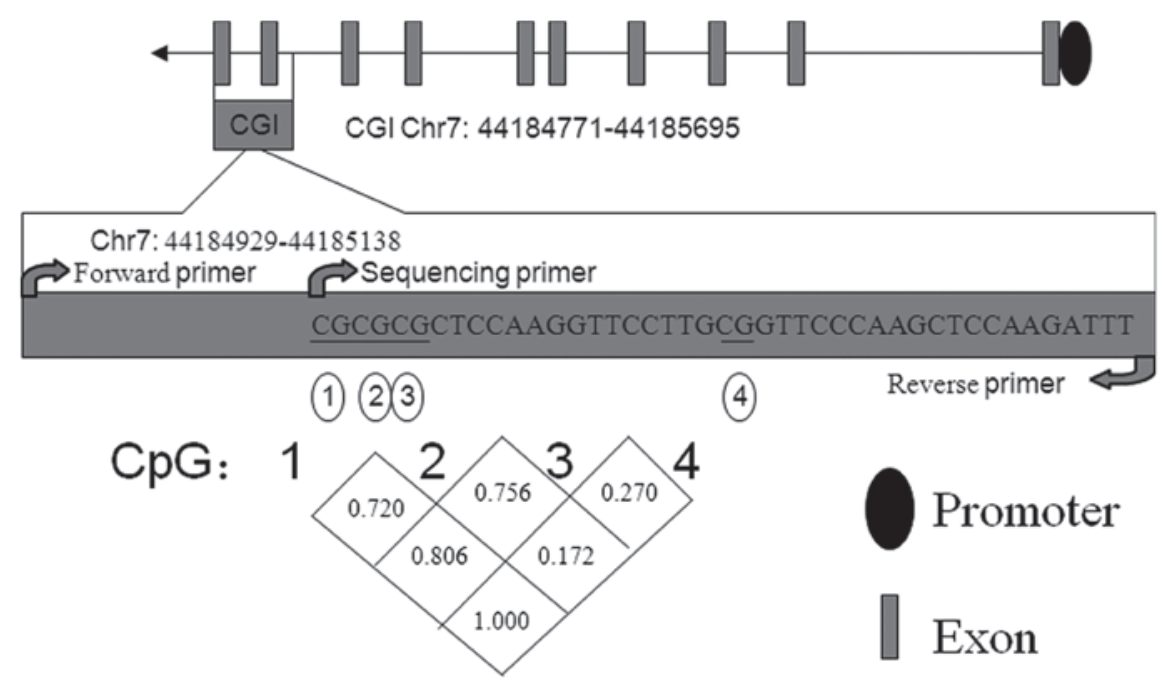

Figure 1. CpG sites assessed in the $G C K$ gene.

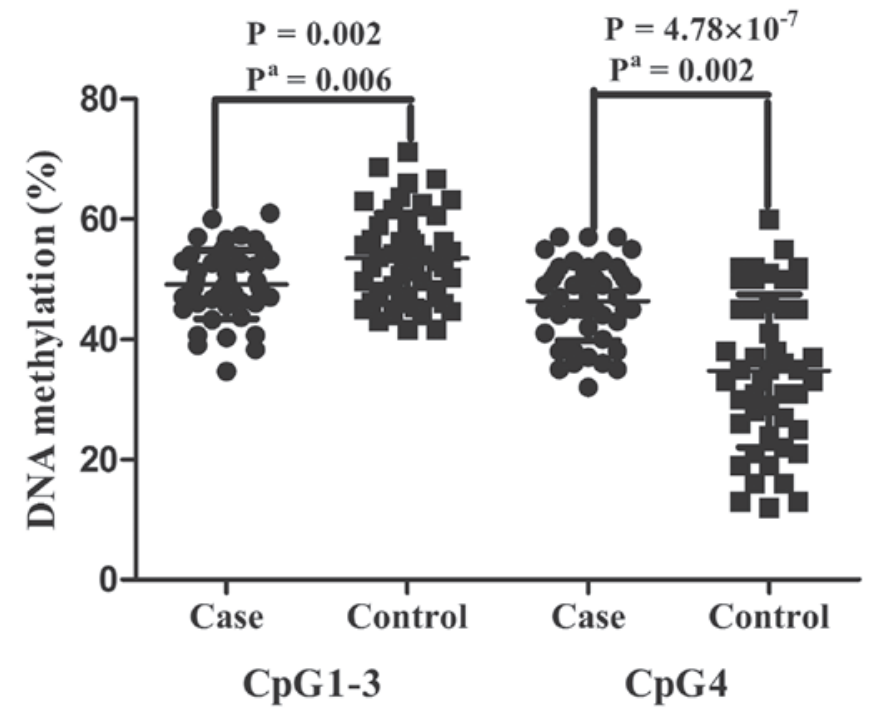

Figure 2. Differences in the DNA methylation of the GCK gene between case $(n=47)$ and control $(n=47)$ subjects. significant correlation between the levels of CpG1-3 methylation and ALT (Fig. 4; r=-0.424; $\mathrm{P}=0.044$ ) was observed in females, while no significant results were obtained for the remaining tests.

\section{Discussion}

Previous studies have reported that $G C K$ polymorphisms were associated with hypertension $(21,22)$. The present study hypothesized that the aberrant $G C K$ gene-body methylation may also induce $\mathrm{EH}$. The results revealed that patients with EH exhibited hypomethylation of CpG1-3 and hypermethylation of $\mathrm{CpG} 4$ in the $G C K$ gene-body, compared with those of the control individuals. The results of the present study regarding the role of $G C K$ methylation in the risk of $\mathrm{EH}$ may provide novel hints to aid the clarification of the pathogenesis of $\mathrm{EH}$ in future.

In the present study, no specific CGI was observed in the human $G C K$ promoter. Gene-body methylation identified 


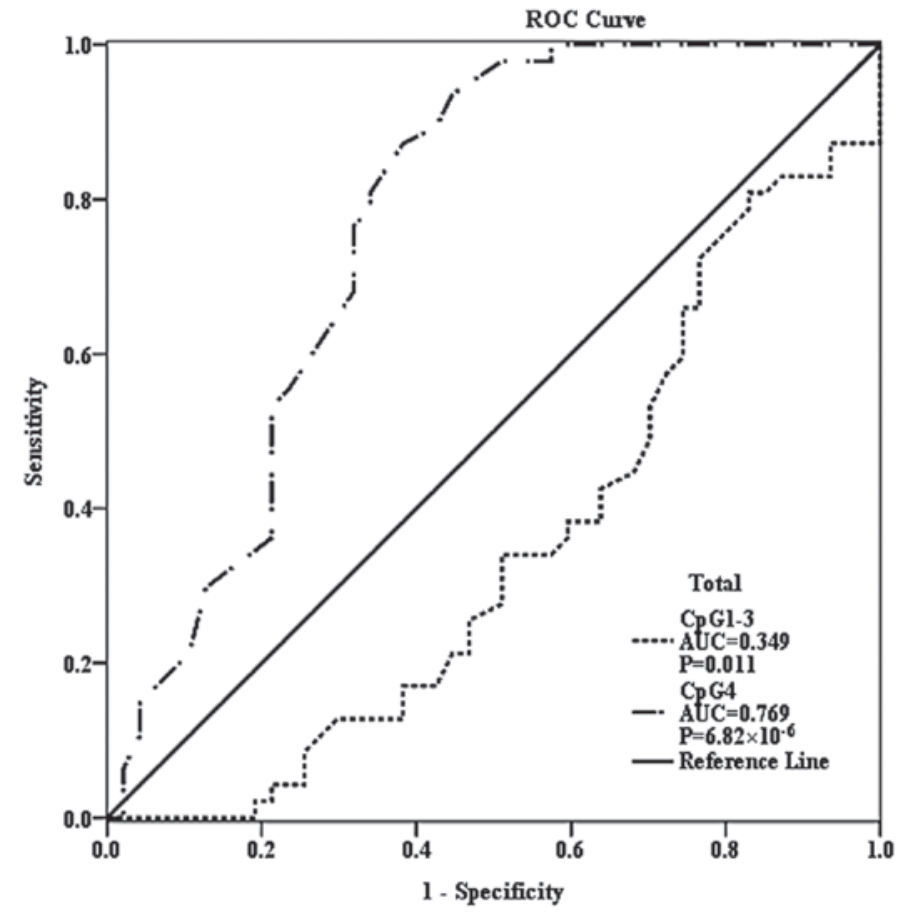

Figure 3. ROC curve demonstrating the DNA methylation of the $G C K$ gene in essential hypertension. ROC, receiver operating characteristic.
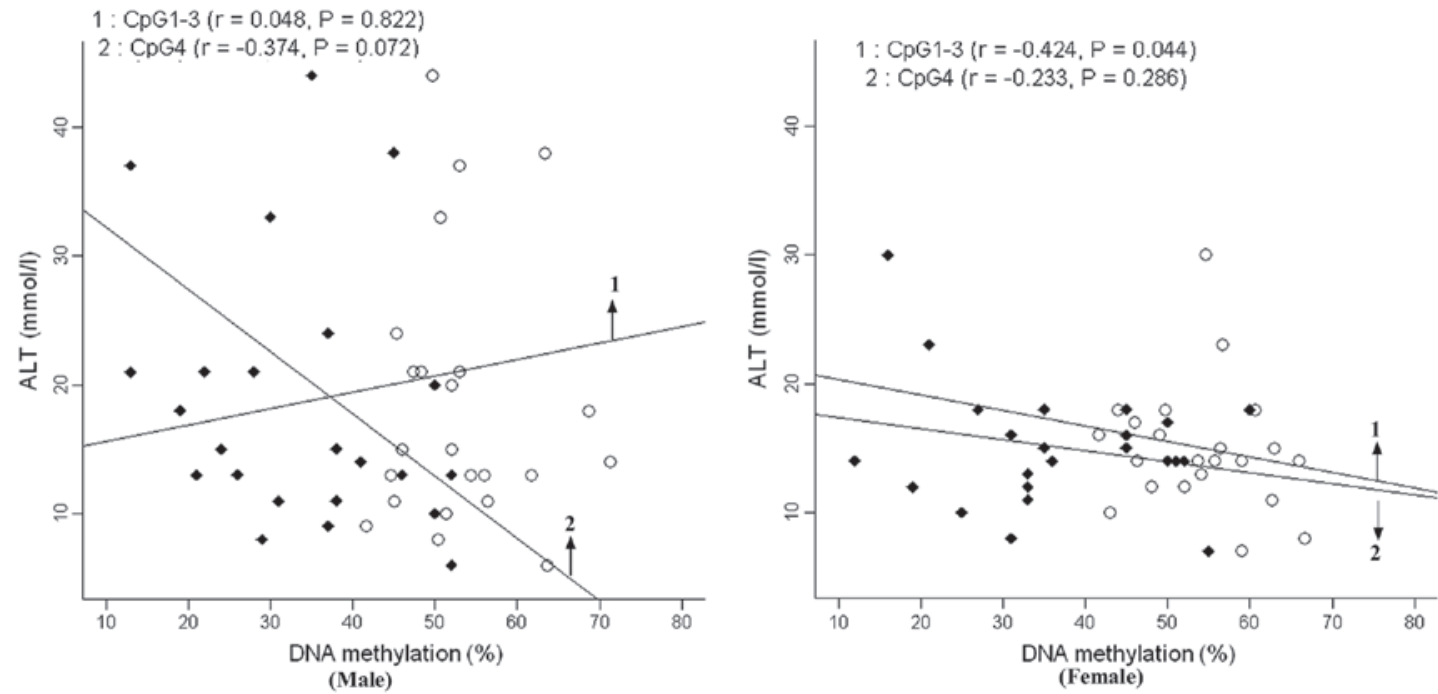

Figure 4. Pearson correlation between the DNA methylation of the GCK gene and ALT in 24 male and 23 female controls. White dots refer to line 1, and black dots refer to line 2. ALT, alanine transaminase.

'orphan promoters', which may be used in the early stages of development (30). Hypermethylation of gene-bodies frequently indicates higher levels of gene expression in human tissues and cell types $(8,31)$. Aberrant methylation of the gene body was observed to contribute to the risk of heart failure (32) and coronary heart disease (23). DNA methylation of gene bodies has major significance in the regulation of gene expression (33). In certain types of human tissue, positive correlation between gene-body methylation and gene expression has been identified $(34,35)$. Gene-body methylation was reported to be significant in regulating cell context-specific alternative promoters in human and mouse tissues (28).
Associations between DNA methylation and age were demonstrated to affect the EH status (16). This observation indicated that EH was affected by genetic and environmental factors, including DNA methylation status and age. Age was previously revealed to be positively correlated with $G C K$ methylation levels (23), however the present study failed to demonstrate this association. No association between age and CpG1-3 or CpG4 methylation was observed (data not shown).

A positive correlation between plasma glucose levels and blood pressure has been previously reported (36). Increased levels of plasma ALT (37) and uric acid (38) were revealed to be associated with hypertension. In the present study, the association of uric acid and plasma glucose with $G C K$ 
DNA methylation levels was not observed, whereas CpG1-3 methylation levels were positively associated with ALT in the female control samples. These results suggested that GCK CpG1-3 methylation may exert its effects on the risk of $\mathrm{EH}$ via regulation of the levels of ALT in females. Ongoing research is required to investigate the specific mechanisms underlying this association.

In conclusion, the results of the present study demonstrated that a hypomethylation level of CpG1-3 and a hypermethylation level of $\mathrm{CpG} 4$ in the $G C K$ gene-body increased the risk of EH. GCK CpG4 methylation may have potential in aiding the prediction of EH risk. The findings provide novel clues to facilitate the elucidation of the pathogenesis of EH.

\section{Acknowledgements}

This study was supported by grants from the National Natural Science Foundation of China (no. 81373094),Zhejiang Provincial Natural Science Foundation of China (no. Y2100857), the K.C. Wong Magna Fund in Ningbo University, Natural Science Foundation of Ningbo City (no. 2011A610037) and the Research Project of Ningbo University (no. XKL11D2124).

\section{References}

1. Lawes CM, Vander Hoorn S and Rodgers A; International Society of Hypertension: Global burden of blood-pressure-related disease, 2001. Lancet 371: 1513-1518, 2008.

2. Xi B, Cheng H, Shen Y, et al: Physical activity modifies the associations between genetic variants and hypertension in the Chinese children. Atherosclerosis 225: 376-380, 2012.

3. Tanira MO and Al Balushi KA: Genetic variations related to hypertension: A review. J Hum Hypertens 19: 7-19, 2005.

4. Xi B, Shen Y, Reilly KH, Wang X and Mi J: Recapitulation of four hypertension susceptibility genes (CSK, CYP17A1, MTHFR and FGF5) in East Asians. Metabolism 62: 196-203, 2013.

5. Xi B, Tang W and Wang Q: Polymorphism near the ATP2B1 gene is associated with hypertension risk in East Asians: A meta-analysis involving 15909 cases and 18529 controls. Blood Press 21: 134-138, 2012.

6. Binder A: A review of the genetics of essential hypertension. Curr Opin Cardiol 22: 176-184, 2007.

7. Whelton PK, He J, Appel LJ, et al: Primary prevention of hypertension: Clinical and public health advisory from The National High Blood Pressure Education Program. JAMA 288: 1882-1888, 2002.

8. Jjingo D, Conley AB, Yi SV, Lunyak VV and Jordan IK: On the presence and role of human gene-body DNA methylation. Oncotarget 3: 462-474, 2012

9. Zemach A, McDaniel IE, Silva P and Zilberman D: Genome-wide evolutionary analysis of eukaryotic DNA methylation. Science 328: 916-919, 2010.

10. Kim MS, Lee J and Sidransky D: DNA methylation markers in colorectal cancer. Cancer Metastasis Rev 29: 181-206, 2010.

11. Kerr KM, Galler JS, Hagen JA, Laird PW and Laird-Offringa IA: The role of DNA methylation in the development and progression of lung adenocarcinoma. Dis Markers 23: 5-30, 2007.

12. Akalin A, Garrett-Bakelman FE, Kormaksson M, et al: Base-pair resolution DNA methylation sequencing reveals profoundly divergent epigenetic landscapes in acute myeloid leukemia. PLoS Genet 8: e1002781, 2012.

13. Smolarek I, Wyszko E, Barciszewska AM, et al: Global DNA methylation changes in blood of patients with essential hypertension. Med Sci Monit 16: CR149-CR155, 2010

14. Kulkarni A, Chavan-Gautam P, Mehendale S, Yadav H and Joshi S: Global DNA methylation patterns in placenta and its association with maternal hypertension in pre-eclampsia. DNA Cell Biol 30: 79-84, 2011.
15. Friso S, Pizzolo F, Choi SW, et al: Epigenetic control of 11 beta-hydroxysteroid dehydrogenase 2 gene promoter is related to human hypertension. Atherosclerosis 199: 323-327, 2008.

16. Zhang LN, Liu PP, Wang L, et al: Lower ADD1 gene promoter DNA methylation increases the risk of essential hypertension. PLoS One 8: e63455, 2013.

17. Liu J, Zhao D, Liu J, Qi Y, Sun J and Wang W: Prevalence of diabetes mellitus in outpatients with essential hypertension in China: A cross-sectional study. BMJ Open 3: e003798, 2013.

18. Iynedjian PB: Molecular physiology of mammalian glucokinase. Cell Mol Life Sci 66: 27-42, 2009.

19. Heredia VV, Thomson J, Nettleton D and Sun S: Glucose-induced conformational changes in glucokinase mediate allosteric regulation: Transient kinetic analysis. Biochemistry 45: 7553-7562, 2006.

20. Kamata K, Mitsuya M, Nishimura T, Eiki Ji and Nagata Y: Structural basis for allosteric regulation of the monomeric allosteric enzyme human glucokinase. Structure 12: 429-438, 2004.

21. Chiang FT, Chiu KC, Tseng YZ, Lee KC and Chuang LM: Nucleotide(-258) G-to-A transition variant of the liver glucokinase gene is associated with essential hypertension. Am J Hypertens 10: 1049-1052, 1997.

22. Yamada Y, Ando F and Shimokata H: Association of polymorphisms of SORBS1, GCK and WISP1 with hypertension in community-dwelling Japanese individuals. Hypertens Res 32: 325-331, 2009.

23. Xu L, Zheng D, Wang L, et al: GCK gene-body hypomethylation is associated with the risk of coronary heart disease. Biomed Res Int 2014: 7, 2014

24. MacMahon S, Peto R, Collins R, et al: Blood pressure, stroke and coronary heart disease: Part 1, prolonged differences in blood pressure: prospective observational studies corrected for the regression dilution bias. Lancet 335: 765-774, 1990.

25. Nadeem M, Ahmed SS, Mansoor S and Farooq S: Risk factors for coronary heart disease in patients below 45 years of age. Pak J Med Sci 29: 91-96, 2013.

26. European Society of Hypertension-European Society of Cardiology Guidelines Committee: 2003 European Society of Hypertension-European Society of Cardiology guidelines for the management of arterial hypertension. J Hypertens 21: 1011-1053, 2003.

27. Perloff D, Grim C, Flack J, et al: Human blood pressure determination by sphygmomanometry. Circulation 88: 2460-2470, 1993.

28. Jiang D, Zheng D, Wang L, et al: Elevated PLA2G7 gene promoter methylation as a gender-specific marker of aging increases the risk of coronary heart disease in females. PLoS One 8: e59752, 2013.

29. Bassil CF, Huang Z, Murphy SK: Bisulfite pyrosequencing. Methods Mol Biol 1049: 95-107, 2013.

30. Illingworth RS, Gruenewald-Schneider U, Webb S, et al: Orphan $\mathrm{CpG}$ islands identify numerous conserved promoters in the mammalian genome. PLoS Genet 6: e1001134, 2010.

31. Maunakea AK, Nagarajan RP, Bilenky M, et al: Conserved role of intragenic DNA methylation in regulating alternative promoters. Nature 466: 253-257, 2010.

32. Movassagh M, Choy MK, Knowles DA, et al: Distinct epigenomic features in end-stage failing human hearts. Circulation 124: 2411-2422, 2011.

33. Jones PA: Functions of DNA methylation: Islands, start sites, gene bodies and beyond. Nat Rev Genet 13: 484-492, 2012.

34. Aran D, Toperoff G, Rosenberg M and Hellman A: Replication timing-related and gene body-specific methylation of active human genes. Hum Mol Genet 20: 670-680, 2011.

35. Ball MP, Li JB, Gao Y, et al: Targeted and genome-scale strategies reveal gene-body methylation signatures in human cells. Nat Biotechnol 27: 361-368, 2009.

36. Cambien F, Warnet JM, Eschwege E, Jacqueson A, Richard JL and Rosselin G: Body mass, blood pressure, glucose, and lipids. Does plasma insulin explain their relationships? Arteriosclerosis 7: 197-202, 1987.

37. Cheung BM, Ong KL, Tso AW, et al: Gamma-glutamyl transferase level predicts the development of hypertension in Hong Kong Chinese. Clin Chim Acta 412: 1326-1331, 2011.

38. Chen DL, Zhang CJ, Fu YH, Mo YJ and Chen FR: Correlation of angiotensin-converting enzyme 2 gene polymorphisms to essential hypertension and ischemic stroke. Nan Fang Yi Ke Da Xue Xue Bao 30: 1890-1892, 2010 (In Chinese). 